\title{
EFFECT OF AIR GAP ENTRAPPED IN FIREFIGHTER PROTECTIVE CLOTHING ON THERMAL RESISTANCE AND EVAPORATIVE RESISTANCE
}

\author{
Hualing $\mathrm{He}^{1,2,3 *}$, Zhicai $\mathrm{Yu}^{2,3}$ \\ ${ }^{1}$ Tianjin Polytechnic University, School of Textiles, Tianjin 300387, China \\ ${ }^{2}$ Eastern Liaoning University, School of Chemical Engineering, Dandong, 118003, China. \\ ${ }^{3}$ Eastern Liaoning University, Liaoning Provincial Key Laboratory of Functional Textile Materials, Dandong, 118003, China. \\ *Corresponding author E-mail: hehualinghe@126.com
}

\begin{abstract}
:
Heat and water vapor transfer behavior of thermal protective clothing is greatly influenced by the air gap entrapped in multilayer fabric system. In this study, a sweating hot plate method was used to investigate the effect of air gap position and size on thermal resistance and evaporative resistance of firefighter clothing under a range of ambient temperature and humidity. Results indicated that the presence of air gap in multilayer fabric system decreased heat and water vapor transfer abilities under normal wear. Moreover, the air gap position slightly influenced the thermal and evaporative performances of the firefighter clothing. In this study, the multilayer fabric system obtained the highest thermal resistance, when the air space was located at position B. Furthermore, the effect of ambient temperature on heat and water vapor transfer properties of the multilayer fabric system was also investigated in the presence of a specific air gap. It was indicated that ambient temperature did not influence the evaporative resistance of thermal protective clothing. A thermographic image was used to test the surface temperature of multilayer fabric system when an air gap was incorporated. These results suggested that a certain air gap entrapped in thermal protective clothing system could affect wear comfort.
\end{abstract}

\section{Keywords:}

Multilayer fabric system, thermal insulation, thermo-physiological comfort, air gap, sweating guarded hotplate

\section{Introduction}

Thermal protective clothing is usually worn by firefighters and other industrial workers to protect the human body against thermal hazards.[1, 2] Firefighting protective clothing usually consists of a shell fabric, a moisture barrier, and a thermal liner. To improve the heat insulation of the multilayer fabric system, the effect of air gap position in multilayer fabric system on thermal protective performance (TPP) has been discussed in several researches.[3-5] These studies indicated that the air gap trapped in multilayer fabrics plays a positive role in TPP of garments. Generally, the second-degree skin burn time is prolonged with increasing air gap size, when the air space varies within $0-6 \mathrm{~mm}$. This was due to higher thermal insulate properties of the static air compared with fibers.[6-9]

Although the presence of air gap under multilayer fabric system plays a positive role on TTP, it may influence negatively on the wear comfort in terms of heat and water vapor transfer from the human body to the ambient environment. Comfort is an important factor to be considered in protective garment design. $[10,11]$ The comfort properties of fabrics are generally classified into three groups, namely, thermo-physiological, tactile, and pressure comfort.[12, 13] Among these factors, thermophysiological comfort is one of the first considerations during heavy work or in hot environments. As we know, the thermal comfort of protective clothing largely depends on the extent to which the clothing influences heat and moisture transport between the human body and surrounding environment.
Thus, the thermo-physiological comfort of thermal protective garments is mainly determined by their heat and water vapor resistances.[14-16] In fact, heat and water vapor transfer is a complex transfer progress from the skin to the environment, when an air gap is presented in the multilayer fabric system. Generally speaking, heat transfer between the human skin and fabric system could pass by heat conduction, heat convection, and heat radiation when a temperature gradient exists between skin and ambient temperature.[17]

Many studies have indicated that the presence of air gap in multilayer fabric system plays an important role in the thermal protection under various heat exposures. In our previous work, the effect of moisture content and air gap position on thermal protective performance (TPP) was also discussed under radiant heat exposure of $21 \mathrm{~kW} / \mathrm{m}^{2}$.[18,19] Despite many researchers having investigated the effect of air gap size or air gap position on TPP, no systematically quantitative study has been conducted to evaluate the effect of air layer distribution in multilayer fabric system on thermo-physiological comfort, particularly in terms of thermal and evaporative resistances. Firefighters usually put on their thermal protective garments and carry around some equipment before they arrived at fire scene (no fire-fighting condition), which impedes heat and moisture exchange between the human body and environment, and therefore, affects achieving a human comfort balance. Thus, heat and water vapor transfer properties under routine condition (no fire-fighting condition) must be considered. Furthermore, no systematic study on heat and water vapor transfer properties 
for multilayer fabric with different ambient temperatures under routine atmospheric environment is available. Hence, this work aims to understand and predict the effect of air gap position coupled with different ambient temperatures on the thermal and evaporative resistances in multilayer fabric system. Based on the critical air gap size for natural convection, it was inferred that the air gap size be set to $5 \mathrm{~mm}$ here to ensure that no convective heat transfer occurred. In order to investigate the thermal and evaporative resistances, the $5 \mathrm{~mm}$ air gap was located at three different positions in multilayer fabric system in this work. The research finding will provide fundamental knowledge to engineer high performance firefighter protective clothing systems.

\section{Experimental}

\subsection{Materials}

In this experiment, one kind of protective fabric assemblies which are commercially available, popularly used, and highperformance were used to simulate the thermal protective textiles. The deliberately selected fabric systems consisted of three layers, namely, outer shell (woven fabric made of aramid fibers), moisture barrier (PTFE laminated on a non-woven face cloth made of aramid fibers), and thermal liner (needle punched nonwoven with cotton woven face cloth). The base physical and structure properties of thermal protective clothing fabrics are displayed in Table 1 and Figure 1, respectively.

The test specimens were cut into $450 \mathrm{~mm} \times 450 \mathrm{~mm}$ squares before testing, and then conditioned in a standard condition $\left(20 \pm 2{ }^{\circ} \mathrm{C}\right.$ and $65 \pm 5 \%$ relative humidity) for $24 \mathrm{~h}$.

\subsection{Test apparatus}

To investigate the effect of air gap located position on heat and water vapor transfer properties of specimen, a sweating guarded hotplate was used to test the thermal and evaporative resistance of multilayer fabric system, according to ISO 11092 standard.[20] Holding frames made of batten were used to generate an air space at different positions in multilayer fabric system. The positions of air gap in the multilayer fabric system were indexed as $A, B$, and $C$, as shown in Figure 2. The holding frame was located at $A, B$, or $C$ position to discuss the effect of air gap position on thermal and evaporative resistances of the sample.

Thermal resistance represents the temperature difference between the two faces of a material divided by the resultant heat flux per unit area in the direction of the gradient. To test the thermal and evaporative resistances of samples, specific environment testing conditions prescribed by this test standard were satisfied using a controlled environmental chamber. For the thermal resistance test, the fabric specimen was placed on porous metal plate surface. The thermal resistance of the sample was achieved using the following equation:

$$
\begin{aligned}
R_{c t} & =\frac{\left(T_{m}-T_{a}\right) \cdot A}{H-\Delta H_{c}} \\
R_{c f} & =R_{c t}-R_{c t 0}
\end{aligned}
$$

where $R_{c f}$ is the fabric resistance, $R_{c t 0}$ is the thermal resistance of bare plate, $R_{c t}$ is the total thermal resistance of the sample

Table 1. Structure features of fabric samples

\begin{tabular}{|c|c|c|c|c|}
\hline Fabric code & Fiber content & Weave structure & Thickness (mm) & Weight $\left(\mathbf{g} / \mathbf{m}^{\mathbf{2}}\right)$ \\
\hline Outer shell & $100 \%$ m-aramid fiber & Woven fabric & 0.60 \\
\hline Moisture barrier & $100 \%$ para-aramid fiber & $\begin{array}{c}\text { PTFE laminated on a non-woven } \\
\text { face cloth Non-woven fabrics with } \\
\text { PTFE member }\end{array}$ & 0.28 & 180 \\
\hline Thermal liner & $100 \%$ para-aramid fiber & $\begin{array}{c}\text { Needle nonwoven with cotton } \\
\text { woven face cloth }\end{array}$ & 2.91 & 120 \\
\hline
\end{tabular}

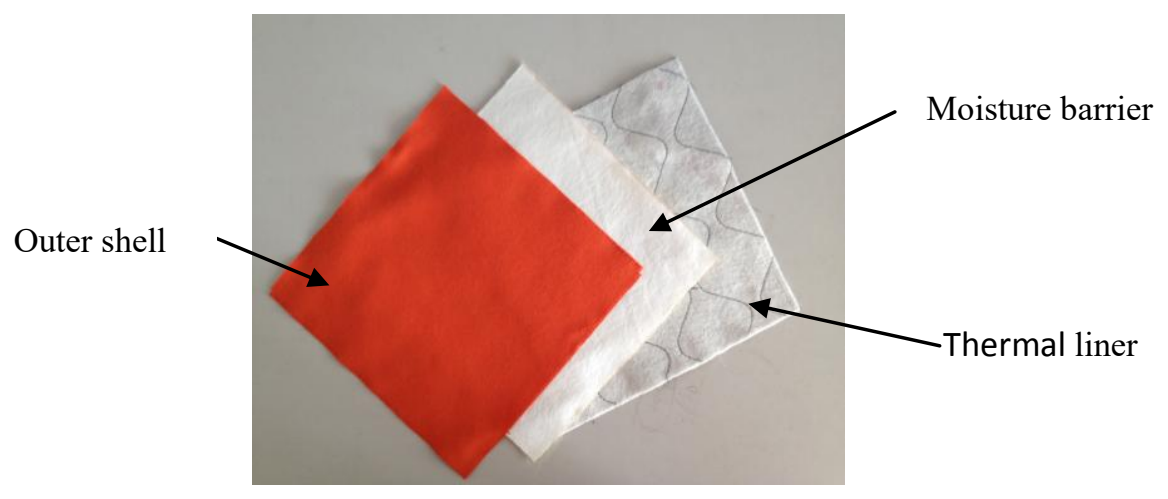

Figure 1. The image of multilayer fabric system used for thermal protective clothing 


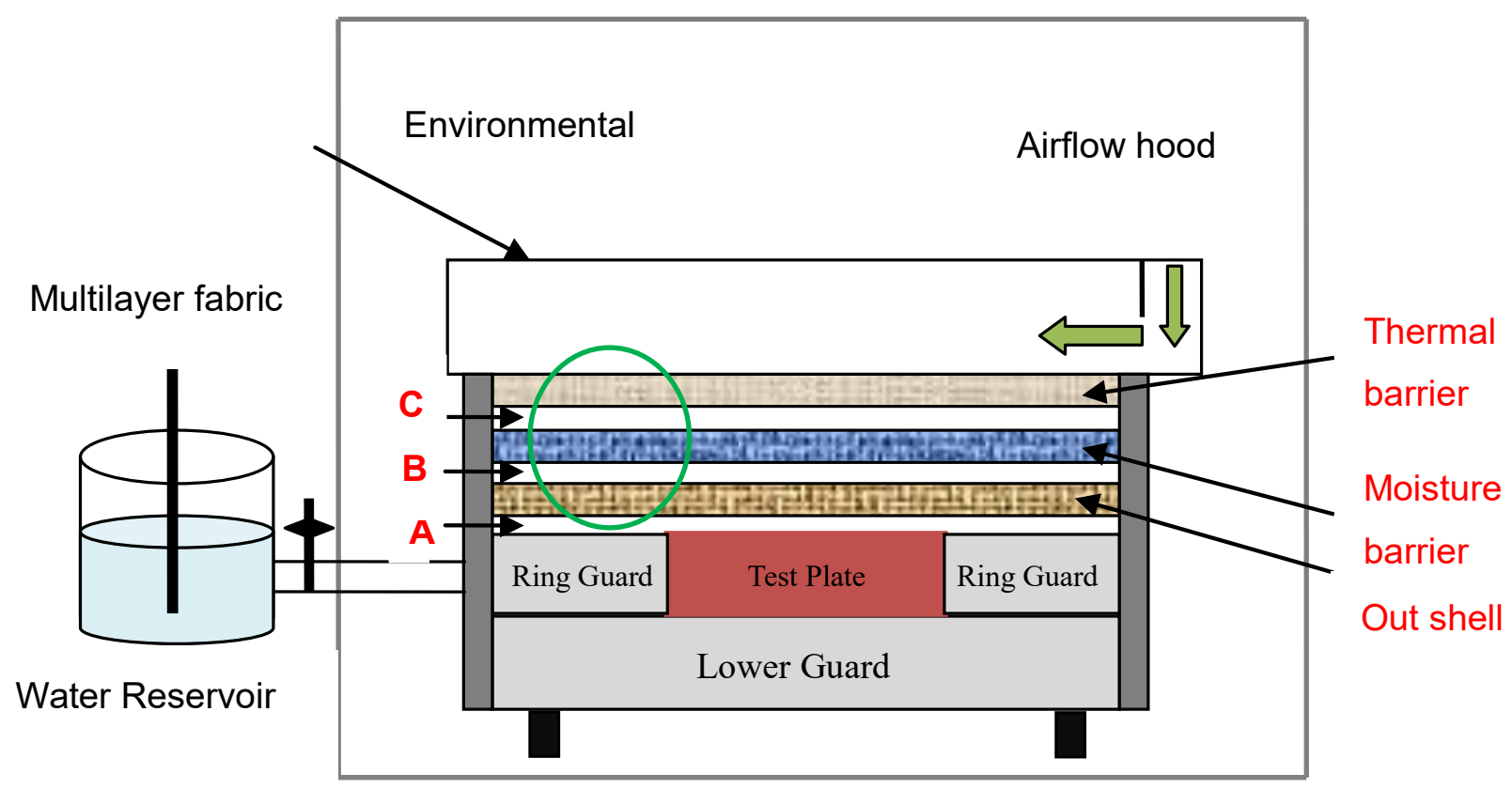

Figure 2. Sweating guarded hotplate testing system

with boundary air layer $\left(m^{2} K / W\right), T_{m}-T_{a}$ is the temperature difference between the plate surface ) and the temperature of a climatic chamber; $\mathrm{H}$ is the heat power supplied to the measuring unit; $\Delta \mathrm{H}_{\mathrm{c}}$ is the correction term for heating power for the measurement of thermal resistance.

Compared with test thermal resistance, distilled water was fed to the surface of the porous plate from a dosing device before evaporative resistance test for the multilayer fabric assemblies. A piece of smooth, water vapor-permeable, liquid waterimpermeable cellophane membrane was fitted over the plate to prevent the direct contact of sample with liquid water. Therefore, only water vapor passed through the test sample. The air temperature was set at $35^{\circ} \mathrm{C}$ in a controlled environmental chamber as per ISO 11092 standards to eliminate the influence of temperature on water vapor. After reaching steady state, the evaporative resistance of the test fabric was obtained by using the following equation:

$$
\begin{array}{r}
R_{e t}=\frac{\left(P_{m}-P_{a}\right) \cdot A}{H-\Delta H_{e}} \\
R_{e f}=R_{e t}-R_{e t 0}
\end{array}
$$

where $R_{\text {ef }}$ is the evaporative resistance of the sample $\left(m^{2} \mathrm{~Pa} / \mathrm{W}\right) ; R_{\text {et0 }}$ is the evaporative resistance of bare plate; $R_{\text {et }}$ is the total evaporative resistance of the sample with boundary air layer $\left(\mathrm{m}^{2} \mathrm{~K} / \mathrm{W}\right)$; is the correction term for heating power for the measurement of water vapor resistance, $P_{m}$ and $P_{a}$ are the water vapor pressure at the surface of heat plate and the air in controlled environmental chamber $\left(\mathrm{P}_{\mathrm{a}}\right)$, respectively. In this work, each prepared sample was tested three times to obtain the thermal and evaporative resistances and then, the mean was obtained.

\section{Results and discussion}

\subsection{Effect of air gap position on thermal and evaporative resistances}

As known, thermal conductivity of air is much lower than that of fabric, and thus, static air is a good insulation for thermal protective clothing. In our previous work, we found that the air gap size had a positive effect on thermal protection performance of multilayer fabric system.[16] However, the effect of air gap position on thermal and evaporative resistances of multilayer fabric system has not been systematically studied. The presence of air gap in multilayer protective clothing system may affect the heat and water vapor transfer through the fabric during normal wear (No firefighting conditions). When the human body generates heat and the water vapor cannot be quickly transferred from human body to the ambient environment, the thermo-physiological comfort of the wearer will decrease. Therefore, the effect of air gap size and position on the thermal comfort of thermal protective clothing is investigated in this work.

To investigate the effect of air gap position on thermal and evaporative resistance of multilayer fabric system, a holding frame with $5 \mathrm{~mm}$ thickness was used to locate at A, B or C position, as shown in Figure 2. Consequently, the same air gap was distributed among different layers of the multilayer fabric system. Figure 3 shows the thermal resistance of the multilayer fabric system with different air gap positions. From Figure 3, it was found that the presence of air gap in the multilayer fabric system obviously increased the thermal resistance performance. This was attributed to the fact that static air is a good insulator which has a lower thermal conductivity than that of fabric. Moreover, similar thermal resistance values were observed when the air gap was located at different positions 
in the multilayer fabric system. In our previous studies, air gap position displayed considerable influence on TPP when exposed to a radiant heat of $21 \mathrm{~kW} / \mathrm{m}^{2}{ }^{\left[{ }^{[18]}\right.}$ This effect is caused by the damage of outer shell when the multilayer fabric system is exposed to high heat source. However, it should be noted that the multilayer fabric system showed a better thermal resistance when the air gap was located at position B compared with other positions. This excellent performance may be caused by the heat convection that occurred when the air gap was located at positions $A$ and $C$ because of the presence of porous hot plate and flowing air in a controlled environmental chamber. Consequently, the heat transfer was enhanced.

\subsection{Effect of air gap position on evaporative resistance}

The effect of air gap position on the evaporative resistance of multilayer fabric system is shown in Figure 4. Compared with the absence air gap in the multilayer fabric system, the presence of air gap significantly increased the absolute value of the evaporative resistance in this study. The evaporative resistance for a multilayer fabric system with an air gap of 5 $\mathrm{mm}$ was increased by $14 \%$ compared with that of without an air space in this study. The results indicated that the evaporative resistance was sensitive to the fabric system with an air gap, which was similar to that of thermal resistance. This result was attributed to the fact that static air in the air gap could increase the water vapor diffusion resistance. Furthermore, the evaporative resistance of multilayer fabric system with different air gap positions was almost unchanged, as shown in Figure 4. This phenomenon can be explained by the fact that the hotplate and ambient air have the same temperature. Thus, natural convection did not occur in the air gap, thereby resulting in unchanged water vapor diffusion resistance in multilayer fabric system. In addition, water vapor diffusion in the multilayer fabric system was mainly influenced by the yarn and fabric structure. Consequently, the air gap position did not show any influence on the evaporative resistance of multilayer fabric system in this study.

\subsection{Effect of ambient temperature on thermal and evaporative resistance performance}

Firefighter protective clothing is often worn by firefighters under routine conditions (no fire-fighting conditions) with different atmospheric temperatures. Ambient temperature is an important variable in our daily life. To date, little research has been conducted on thermal comfort property of thermal protection garments under routine conditions as uniform. Therefore, the present results will provide beneficial guidance for designing thermal protective clothing. To investigate the effect of ambient temperature on thermal resistance performance of multilayer fabric system under routine conditions, the air gap position was located at fixed position $B$ and the air gap size was set at $5 \mathrm{~mm}$ in this work. Figure 5(a) shows the effect of ambient temperature on thermal resistance $\left(R_{c f}\right)$ performance of the multilayer fabric system. It is clear that the $R_{c f}$ with an air gap was higher compared with that without an air gap. Moreover, when the ambient temperature changed from $20^{\circ} \mathrm{C}$ to $40^{\circ} \mathrm{C}$, the $R_{c f}$ of the multilayer fabric system without an air gap size showed almost no change. This result can be explained by the fact that thermal conductivity is the inherent property of the fiber. However, we also found that the $R_{c f}$ of multilayer fabric system with an air gap decreased slightly with increasing ambient temperature because of the static air existing in the protective clothing. The thermal resistance $\left(R_{c t 0}\right)$ of bare plate also exhibited similar behavior, as shown in Figure $5(b)$. $R_{c t 0}$ decreased by $32 \%$ when the ambient temperature increased from $20^{\circ} \mathrm{C}$ to $40^{\circ} \mathrm{C}$. This change can be explained by the fact that the heat transfer coefficient $\left(h_{f}, E\right)$ decreases slightly under dry conditions, whereas the other term increases quickly because of the radiant heat. ${ }^{[21]}$ The above analysis accounts for the decrease of thermal resistance with the increasing of ambient temperature.

The effect of temperature on the evaporative resistance of multilayer fabric system with $5 \mathrm{~mm}$ air gap size at position $B$ is shown in Figure 6. From Figure 6, it was found that the presence of air gap obviously enhanced the evaporative resistance compared with that of without an air gap for the multilayer fabric system. This result indicated that static air also displayed a certain amount of resistance to vapor diffusion. The presence of air gap means increasing the thickness of whole fabric system, thereby increasing the absolute value of the

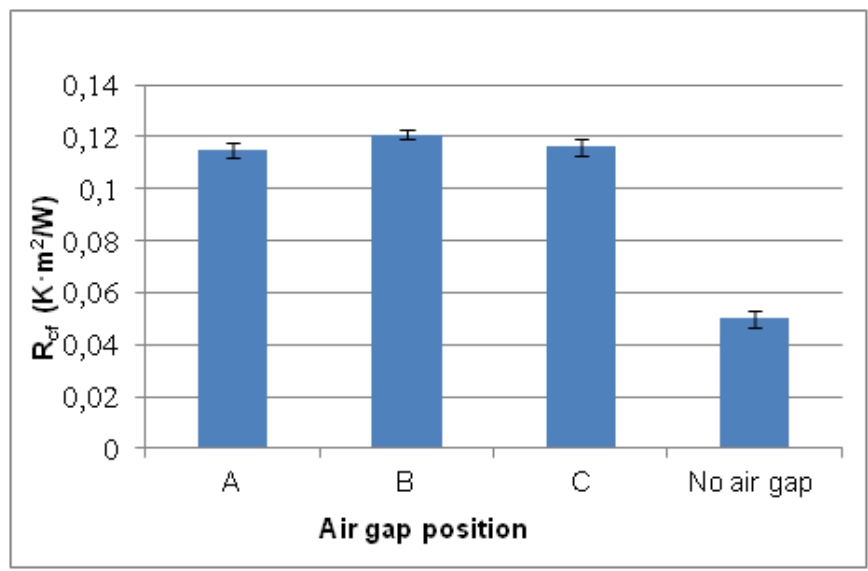

Figure 3. Comparison of $\mathrm{R}_{\mathrm{cf}}$ for multilayer fabric system with the air gap at different position

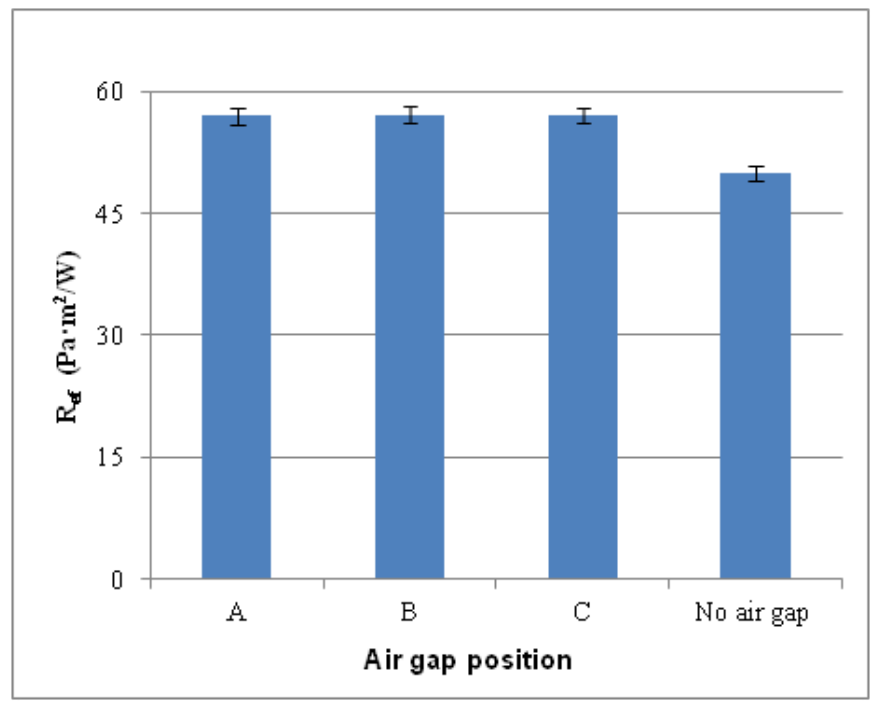

Figure 4. Comparison of $\mathrm{R}_{\mathrm{ef}}$ for multilayer fabric system with air gap at different positions 

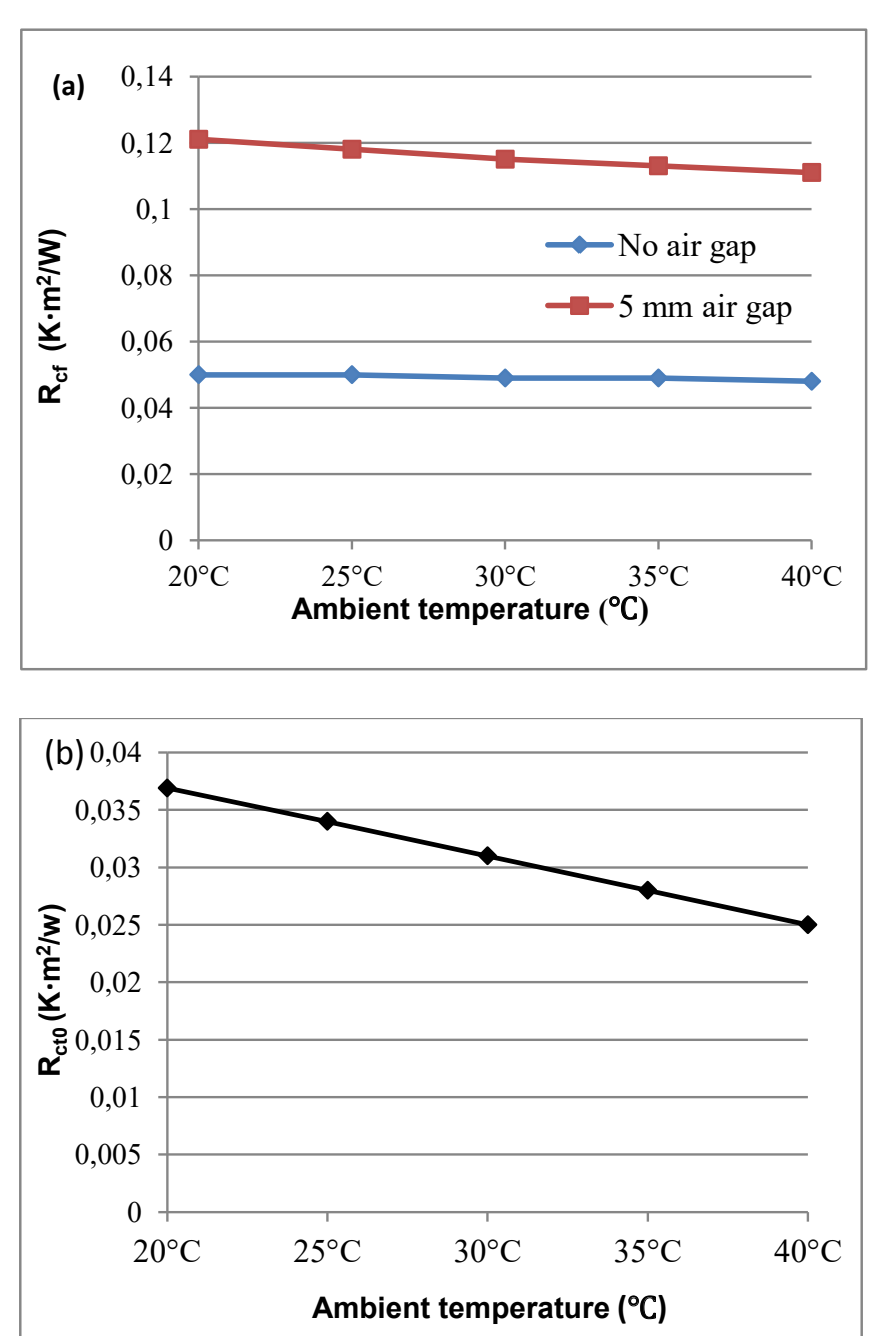

Figure 5. Effect of ambient temperature on thermal resistance (a) $R_{c f}$ and (b) $R_{c t 0}$ (with $5 \mathrm{~mm}$ air gap at position $\mathrm{B}$ ).

evaporative resistance. Additionally, almost no obvious variety was observed for the evaporative resistance $\left(R_{e f}\right)$ in a certain temperature range. The result suggested that the evaporative resistance was not sensitive to ambient temperature, which may be explained by the reason that water vapor diffusion in the multilayer fabric system was mainly influenced by the yarn and fabric structure, when the multilayer fabric system had the same air gap size at a different position.

\subsection{Effect of air gap size on thermal and evaporative resistance of multilayer fabric system}

In this work, the effect of air gap size on thermal and evaporative resistances was also investigated when air space was located at specific position B. Figure 7 shows an almost linear relation between the air space size and thermal resistance when the air gap size was below $12 \mathrm{~mm}$. This observation suggested that the increasing of air gap can effectively decrease the heat transfer from human body to the atmospheric environment. Therefore, increasing the air gap size in multilayer fabric system will decrease the physiological comfort of the wearer. On the other hand, it was also indicated that static air played an excellent heat insulation performance. For the evaporative resistance of tested samples, the results also show an overall increasing trend with increasing air gap size. However, the thermal and

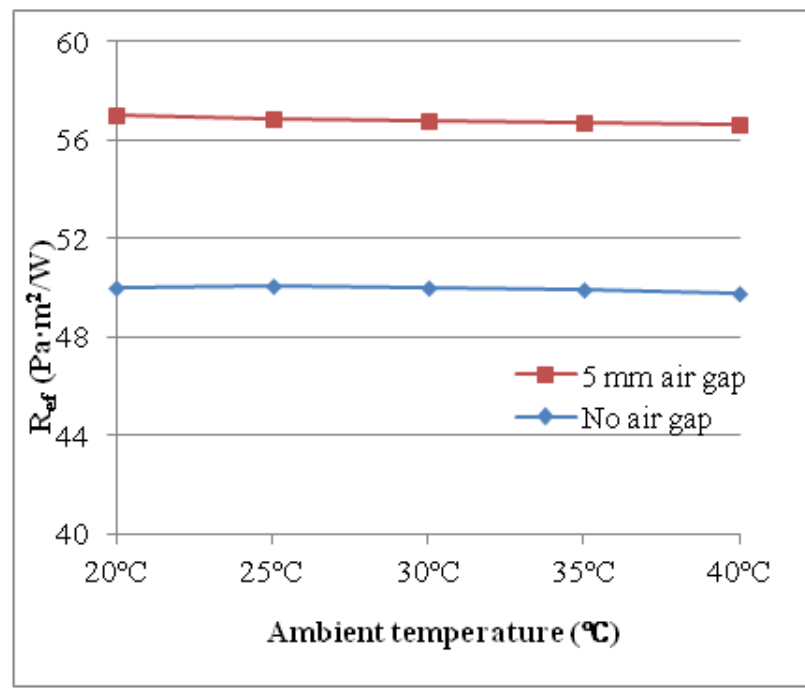

Figure 6. Effect of ambient temperature on evaporative resistance $R_{\text {ef }}$ (with $5 \mathrm{~mm}$ air gap at position $B$ ).

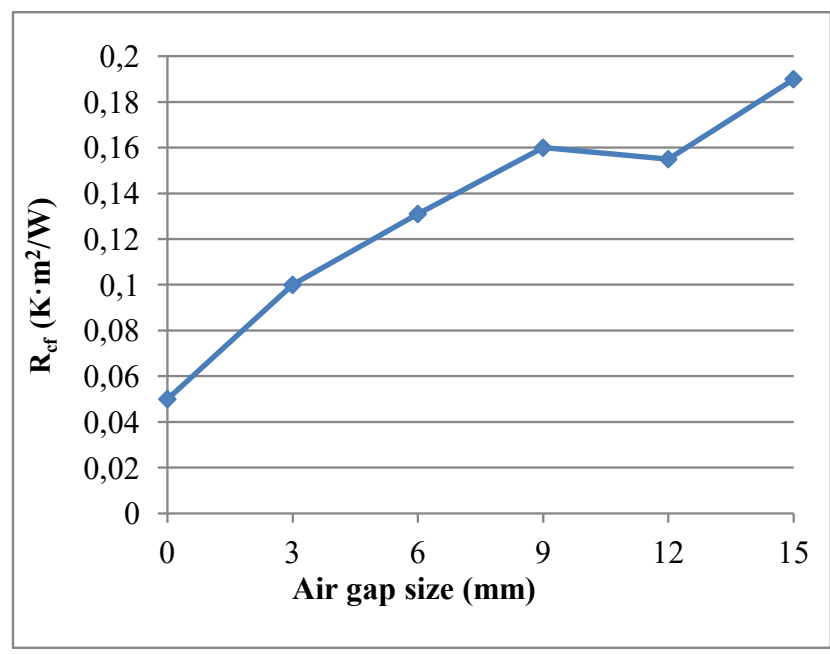

(a)

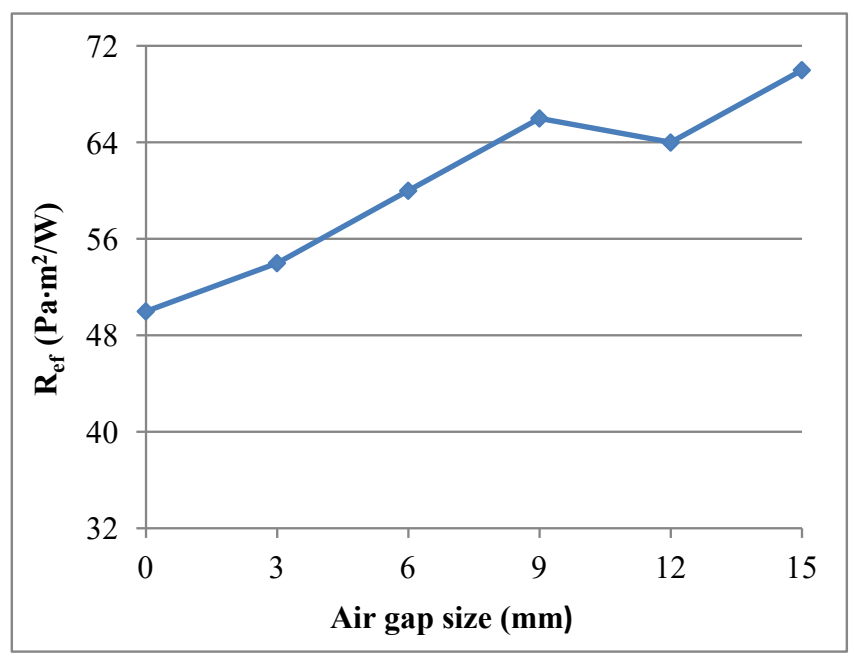

(b)

Figure 7. Comparison of thermal resistance $R_{c f}(a)$ and evaporative resistance $R_{\text {ef }}(b)$ for multilayer fabric system with different air gap sizes 
evaporative resistances decreased when the air gap size reached up to $12 \mathrm{~mm}$ and increased again thereafter. This was due to the natural convection that would take place in multilayer fabric system when the air gap size was approximately $12 \mathrm{~mm}$. The emergence of natural convection changed the water vapor transfer mode from molecular diffusion to convective mass transfer, thereby enhancing the heat and humidity transfer abilities.

\subsection{Thermographic image of multilayer fabric system}

An infrared thermographic camera (FLIR Systems, USA) was further used to assess the effect of air gap on the thermal insulation property of the thermal protective clothing in this work. The use of an infrared thermographic camera could accurately show the surface temperature of multilayer fabric system. In this research, the hot plate was set at $35^{\circ} \mathrm{C}$ to simulate the human body temperature and test the surface temperature of multilayer fabric system. Five test indicators (maximum temperature, minimum temperature, spot temperature, reflection temperature and radiance) were obtained using this test instrument. To investigate the effect of air gap on thermal insulation performance of multilayer fabric system, a $5 \mathrm{~mm}$ air gap was also located at a fixed position B. The infrared thermographic camera was placed approximately $50 \mathrm{~cm}$ away from the heated samples and the test was carried out in a standard atmosphere at $20 \pm 2{ }^{\circ} \mathrm{C}$ and $60 \pm 5 \%$ relative humidity. ${ }^{[22]}$ The comparison between the multilayer fabric system with and without an air gap is shown in Figure 8 and Table 2, respectively.

For the thermal image, different colors represent different temperatures for the tested object. Bright color represents

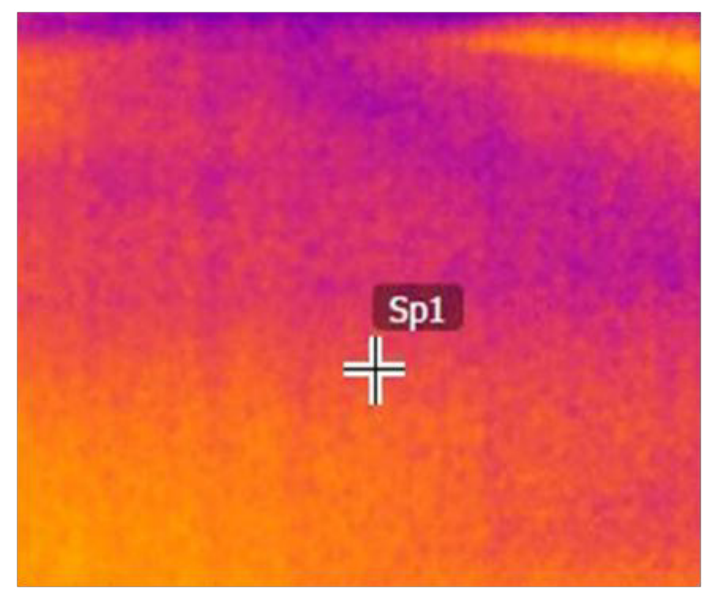

(a) With an air gap high temperature for the test area. Figure 8 shows that the test specimen without an air gap displayed a brighter color than that with an air gap for multilayer fabric system. It means that the presence of air gap could increase the thermal insulation property of the fabric. Table 2 lists the test data for the specimens. For the same test area, the outer layer of the multilayer fabric system without an air gap showed higher maximum and minimum temperature compared with that with an air gap. Differences were also observed for the same spot, as shown in Table 2. The preliminary test results further confirmed that the presence of static air could reduce the thermal conductivity from the human body to the ambient environment in the thermal protective clothing. Although the presence of air space can improve the thermal protective performance exposed to fire or other high heat source, it will also affect the thermo-physiological comfort of wear under routine environment.

\section{Conclusions}

Air space is often designed in clothing to increase the thermal insulation capability and improve the thermal protection performance of firefighter protective clothing. The presence of air space could impede the thermal hazards to the firefighter and may also affect wear comfort under the condition of strenuous physical activity. In this work, we attempted to discuss the effect of air gap on thermo-physiological comfort of multilayer fabrics system under routine condition (no firefighting condition).

Overall, the results obtained showed that the presence of air gap weakened the transfer of heat and water vapor from

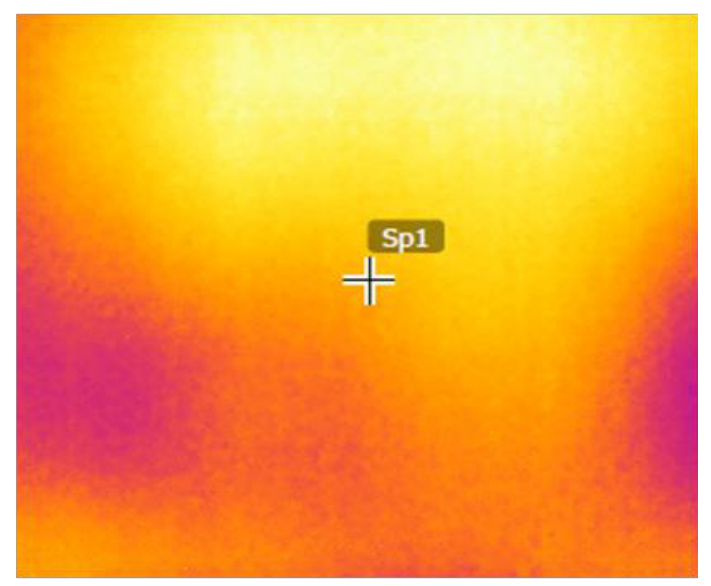

(b) Without an air gap

Figure 8. Thermographic image of multilayer fabric system

Table 2. Results of tested surface temperature

\begin{tabular}{|c|c|c|c|c|c|}
\hline Samples & Radiance & $\begin{array}{c}\text { Reflection } \\
\text { temperature }\end{array}$ & $\begin{array}{c}\text { Maximum } \\
\text { temperature }\end{array}$ & $\begin{array}{c}\text { Minimum } \\
\text { temperature }\end{array}$ & $\begin{array}{c}\text { Spot 1 } \\
\text { temperature }\end{array}$ \\
\hline With an air gap & 0.95 & $20^{\circ} \mathrm{C}$ & $27.9^{\circ} \mathrm{C}$ & $23.9^{\circ} \mathrm{C}$ & $27.8^{\circ} \mathrm{C}$ \\
\hline Without an air gap & 0.96 & $20^{\circ} \mathrm{C}$ & $29.5^{\circ} \mathrm{C}$ & $27.3^{\circ} \mathrm{C}$ & $28.4^{\circ} \mathrm{C}$ \\
\hline
\end{tabular}


the human body to the ambient environment under routine conditions. Furthermore, we also found that the air gap position displayed a different influence on multilayer fabric system in terms of thermal and evaporation insulation properties under the same test conditions. The test results indicated that the specimen showed the highest thermal resistance when the air space was located at position B. However, almost no influence was observed on the evaporative resistance of the multilayer fabric system. In addition, an ambient temperature showed a different effect on thermal protective clothing when a specific air space was present. The results showed that an increase in the ambient temperature could slightly decrease the thermal resistance but exhibited no influence on the evaporative resistance of the sample. Thermographic image was used to reconfirm that the presence of air gap decreased the heat transfer property of the multilayer fabric system.

In this study, only some factors influencing the thermophysiological comfort in terms of thermal and evaporative resistances were investigated. Other factors, such as a wide range of ambient temperature, microclimate, and fabric construction parameters, will be considered in future work. The above results hope to provide helpful guidance to the designer of firefighter protective clothing.

\section{Acknowledgement}

This research was supported by the financial support from the youth fund project of Eastern Liaoning University (BS004; 2015QN004; 2015QN003) and Education Department Funds of Liaoning Province (No. L2015188). The authors are also grateful to Liaoning Key Laboratory of Functional Textile Materials for providing research materials and test equipment.

\section{References}

[1] Lu Y.H., Song G.W., Li J. (2013). Analysing performance of protective clothing upon hot liquid exposure using instrumented spray manikin. Ann Occup Hyg, 57 (6), 793804.

[2] Irzmanska E. (2016). The microclimate in protective fire fighter footwear: foot temperature and air temperature and relative humidity. Autes Res J, 16 (2), 75-79.

[3] Keiser C., Becker C., Rossi R.M. (2008). Water vapor transport and absorption in multilayer protective clothing fabrics. Textile Res J, 78(7), 604.

[4] Wang Y.Y., Lu Y.H., Li J., Pan J.H. (2012). Effects of air gap entrapped in multilayer fabrics and moisture on thermal protective performance. Fiber Polym, 13 (5), 647-652.

[5] Li J., Lu Y.H., Li X.H. (2012). Effect of relative humidity coupled with air gap on heat transfer of flame-resistant fabrics exposed to flash fires, Textile Res J, 82(12), 12351243.

[6] Tian M., Wang Z.L., Li J. (2016). 3D numerical simulation of heat transfer through simplified protective clothing during fire exposure by CFD. Int J Heat Mass Tran, 93(2), 314-321.

[7] Torvi, D. A., Dale, J. D., Faulkner, B. (1999). Influence of air gaps on bench-top test results of flame resistant fabrics. $J$ Fire Prot Eng, 10(1), 1-12.
[8] Song G.W. (2007). Clothing air gap layers and thermal protective performance in single layer garment. J Ind Text, 36(3), 193-205.

[9] Song G.W., Paskaluk S., Sat., Crown E.M., Dale J.D., Ackerman M. (2011). thermal protective performance of protective clothing used for low radiant heat protection. Textile Res J, 81(3), 311-323.

[10] Onofrei E., Codau T.C., Petrusic S., Bedek G., Dupont D., Soulat D. (2015). Analysis of moisture evaporative from underwear designed for fire-fighters. Autes Res J, 15 (1), 35-47.

[11] Yu Z.C., Zhang J.F., Lou C.W., He H.L., Chen A.B., Lin J.H. (2015). Moisture comfort and antibacterial properties of elastic warp-knitted fabrics, Autes Res J, 15 (1), 60-66.

[12] Yu Z.C., Zhang J.F., Lou C.W., He H.L., Chen A.B., Lin J.H. (2015). Wicking behavior and dynamic elastic recovery properties of multifunction elastic warp-knitted fabrics. Textile Res J, 85(14), 1486-1496.

[13] Yanılmaz M., Kalaoglu F. (2012). Investigation of wicking, wetting and drying properties of acrylic knitted fabrics. Textile Res J, 82(8), 820-831.

[14] Xin L.S., Li J. (2016). The relation between thermal protection performance and total heat loss of multi-layer flame resistant fabrics with the effect of considered. Fiber Polym, 17 (2), 289-297.

[15] Udayraj., Talukdar, P., Das, A., Alagjrusamy, R. (2016). Heat and mass transfer through thermal protective clothing $-A$ review. Int J Therm, 106, 32-56.

[16] Gilewicz, P., Cichocka, A., Frydrych, L. (2016). Underwear for protective clothing used by foundry worker, Fibers Textile East Eur, 24(5), 96-99.

[17] Ding D., Tang T., Song G.W., McDonald A. (2010). Characterizing the performance of a single-layer fabric system through a heat and mass transfer model - Part I: Heat and mass transfer model. Textile Res J, 81(4), 398411.

[18] He H.L., Yu Z.C., Song G.W. (2016). The effect of water vapor and air gap on the thermal protective performance of fabric assemblies used by wildland firefighters. J Text Inst, 107 (8), 1030-1036.

[19] Yoo, S., Barker, R.I. (2005). Comfort properties of heatresistant protective workwear in varying conditions of physical activity and environment. Part I: Thermophysical and Sensorial Properties of Fabrics. Textile Res J, 75(7), 523-530.

[20] Ahn, H.W., Park, C.H., Chung, S.E. (2010). Waterproof and breathable properties of nanoweb applied clothing. Textile Res J, 81(14), 1438-1447.

[21] Ding D., Tang T., Song G.W., McDonald A. (2011). Characterizing the performance of a single-layer fabric system through a heat and mass transfer model - Part II: Thermal and evaporative resistances. Textile Res J, 81(9), 945-958.

[22] Curteza A., Cretu V., Macove L., Poboroniuc M. (2016). The manufacturing of textile products with incorporated electrodes. Autes Res J, 16 (1), 13-18. 